\title{
O MÉTODO DO CUSTEIO DIRETO
}

\section{WOLFGANG SCHOEPS}

\begin{abstract}
De fácil aplicação contábil, o custeio direto fornece bases mais amplas para enfrentar a concorrência de preços e permite estabuelecer diretrizes financeiras mais flexiveis.
\end{abstract}

A constante procura de métodos e processos úteis à orientação do administrador de cúpula tem, no campo da contabilidade industrial, levado a um sistema de análise de custos de inestimável valor prático para as nossas emprêsas. Trata-se do chamado Método do Custeio Direto ("Direct Costing"), que contribui para :

* aumentar o poder competitivo da emprêsa;

* planejar melhor seu resultado econômico;

* determinar preços em função da capacidade instalada de produção e, ao mesmo tempo, das condições vigentes no mercado.

Este artigo tem por objetivo demonstrar como o custeio direto é realizado, quais sāo as suas vantagens perante outros métodos de contabilização de custos e quais são algumas das suas aplicações na prática administrativa.

\section{o Conceito do Custeio Direto}

Visa o custeio direto dar maior flexibilidade à determinação dos preços de venda e do lucro da emprêsa, separando as despesas fixas de fabricação, de vendas e de administração

WOLFGANG SCHOEPS. - Professor Adjunto do Departamento de Administração da Produção e Coordenador do «Curso Intensivo para Administradores» da Escola de Administração de Emprêsas de São Paulo. 
(que são debitadas diretamente à conta de lucros e perdas) dos custos diretamente variáveis com a produção.

Já nos seus primórdios, de 1892 a 1902, a literatura especializada da contabilidade de custos mencionava a prática de debitar as despesas gerais de fabricação à demonstração de lucros e perdas. Autores norte-americanos voltaram ao assunto na década de 1930, mas foi, principalmente, nos períodos de freqüentes variações da atividade econômica que ocorreram no mundo inteiro desde 1950, que ficou patente a vantagem de determinar os custos independentemente de critérios de absorção direta das despesas gerais de fabricação.

O têrmo "custeio direto" foi, pela primeira vez, empregado por JONATHAN N. HARRIS em 1936, em um trabalho publicado no "N.A.C.A. Bulletin".

A definição e descrição mais divulgadas e aceitas de método foram publicadas pela mesma revista em janeiro de 1951, num artigo de $\mathrm{W}$. W. NEIKIRK, com os seguintes conceitos :

"O custeio direto deve ser definido como uma separação entre os custos de fabricação e os custos variáveis com o volume de produção. Para determinar o custo do produto em estoque, assim como o custo do produto vendido, sòmente se computam os custos primários e os custos indiretos variáveis. As despesas fixas referentes à fabricação, vendas e administração serão debitadas a lucros e perdas. E importante notar, porém, que o custeio direto consiste, em primeiro lugar, na separação de despesas, e sòmente em segundo lugar, num método para deterininar o valor dos produtos em estoque. Na análise do lucro pelo método do custeio direto, todos os itens referentes ao custo e às despesas são colocados em ordem decrescente de acôrdo com sua variabilidade. O primeiro item a ser deduzido da receita bruta de vendas é o custo variável de fabricação. Também a parte diretamente variável das despesas de vendas como as comissões, por exemplo, deve ser deduzida. A importância líquida após estas dedu- 
ções é convencionalmente chamada de margem comercial. As deduções seguintes serão tôdas de natureza fixa, isto é, despesas fixas de administração, vendas e fabricação, obtendo-se assim o lucro líquido da emprêsa, anterior à tributação sôbre a renda, para determinado período" (1).

Convém lembrar que o sistema de rateio de despesas gerais sempre tem por base critérios que podem ser alterados de acôrdo com a apreciação do modo e do grau no qual as despesas gravam a produção e a venda de um produto. Portanto, são critérios bastante subjetivos, dentro dos limites totais das despesas, e um administrador esclarecido dificilmente aceitará um cálculo de custo como sendo a expressão absoluta e matemática da realidade financeira. Procurará antes conhecer minuciosamente quais foram as premissas utilizadas para chegar aos resultados apresentados.

A moderna administração necessita de demonstrações contábeis sôbre as quais possa basear decisões quanto à sua política referente a vendas, preços, produção, estoques, financiamentos, expansão, enfim, a todos os elementos ligados à sua gestão. Estas demonstrações contábeis ou mesmo estatísticas constituem a chamada "contabilidade administrativa", com a função precípua de orientar o administrador, ao passo que a contabilidade fiscal continua a satisfazer primordialmente as exigências tributárias.

O sistema do custeio direto tem contribuído muito para simplificar a tarefa de rateio de custos e despesas. Contràriamente ao procedimento usado no sistema de custeio por absorção, o custo do produto acabado em estoque não inclui as despesas fixas de fabricação.

\section{Custeio Direto e Custeio por Absorção}

A contabilidade de custo industrial por absorção fornece, normalmente, os seguintes elementos ao administrador :

(1) W. W. Neikirk, «How Direct Costing Can Work for Management» N. A. C. A. Bulletin, janeiro de 1951, pg. 525 . 
R.A.E.

a) - custo primário, representando os gastos diretos tais como mão-de-obra e materiais;

b) - custo de fabricação, representando a soma do custo primário com as despesas de fabricação (material e mão-de-obra indiretos, assim como as despesas gerais da fábrica);

c) - custo total, representando a soma do custo de fabricação com as despesas gerais de administração e as despesas de vendas.

No método do custeio direto, para determinado período, às despesas fixas de fabricação são adicionadas as despesas fixas de administração e de vendas, que, acrescidas do custo primário (ou custo variável) darão o custo total. Nesse método, a diferença entre o produto das vendas e o custo primá. rio constitui a chamada "margem comercial" ou "contribuição às despesas gerais, inclusive lucro". Exemplificando :

\section{Cr\$ Cr\$}

VENDAS - Receita ........ $\quad 1.000 .000,00$

menos

CUSTO VARIAVEL DE

FABRICAÇAOO :

Materiais ...............

$175.000,00$

Mão-de-obra $\ldots \ldots \ldots \ldots \ldots . \quad 225.000,00$

$400.000,00$

CONTRIBUIÇÃO AS DESPESAS

GERAIS INCLUSIVE LUCRO

OU "MARGEM COMERCIAL"

menos

DESPESAS GERAIS :

Despesas fixas de fabricação

Despesas de Vendas .......

Despesas Administrativas ..
$200.000,00$

$100.000,00$

$100.000,00$
$400.000,00$

LUCRO LIQUIDO :

$200.000,00$

Quando existe grande volume de produção e quando parte apreciável dêste fica em estoque, não se apresentará um qua- 
dro errôneo de despesas absorvidas se se aplicar o custeio direto. Por outro lado, quando o estoque passa a abastecer o mercado, estando a produção reduzida, então a mercadoria vendida do estoque passa a absorver parte das despesas gerais de fabricação, pois, do contrário, o reduzido volume de produção teria, necessàriamente, que arcar com a absorção destas mesmas despesas. Conseqüentemente, o resultado da conta de lucros e perdas refletirá, mensalmente, uma posição mais equilibrada da emprêsa. Além do mais, será mais fácil à administração da emprêsa determinar o preço para cada venda, pois, conhecendo-se o custo primário do produto pôsto em estoque, será possivel raciocinar em têrmos de lucro marginal para cada venda, tornando, assim, mais competitiva a política de vendas e a fixação de preços.

No sistema do custeio direto, o custo primário de fabricação, acrescido das despesas diretas de vendas, corresponde sempre às quantidadıs vendidas, náo havendo, desta forma, a absorção de despesas no caso de aumentar-se o estoque. A produção não vendida resultaria em lucro aparentemente maior, mas não realizado.

Pelo sistema de custos absorvidos, o custo da produção será mais elevado durante os meses nos quais é fornecida maior quantidade de produtos pelo estoque existente do que pela fabricação. Estas flutuações do custo contábil normalmente não justificam mudanças de preços. Para o administrador incumbido da determinação da política de preços, o item "contribuições às despesas gerais inclusive lucro" representa um dado mais flexível para base de decisões, pois, aquêle imediatamente pode julgar se esta contribuição é suficiente ou não, alterando, respectivamente, os preços e a nargem de lucro em função das condições vigentes no mercado.

O estudo das possibilidades de lucro que, eventualmente, poderia resultar da venda adicional de produtos com preços inferiores aos preços correntes, mas superiores ao custo variável, é objeto da análise marginal, ou seja, da análise do lucro adicional a ser obtido pela venda de quantidades tam- 
bém adicionais em relação às quantidades básicas necessárias para produzir determinado resultado financeiro.

A análise marginal aplicada às finanças da emprêsa visa aumentar o lucro total, alterando-se os preços em função das quantidades vendáveis, o que pressupõe um conhecimento básico do comportamento da demanda. Sem êste conhecimento será sempre perigoso lançar quantidades adicionais a preços inferiores aos preços normais. E esta redução dos preços deverá apenas atingir setores ou consumidores isolados, sob pena de destruir a estrutura de preços da emprêsa.

Diversas emprêsas nacionais, fabricantes de equipamento industrial sob encomenda, utilizam, atualmente, êste procedimento para reduzir os preços nos seus orçamentos a fim de obter novas encomendas. E efetuada uma redução progressiva dos preços orçados, à medida que é ultrapassado o volume de produção que corresponde à absorção das despesas fixas e à retribuição do capital. Desta maneira, a emprêsa torna-se cada vez mais competitiva com o aumento de sua produção.

\section{Um Exemplo Numérico}

Devido às diferentes premissas, o lucro calculado pelo custeio direto e o lucro apurado pela contabilidade tradicional de rustos por absorção podem divergir bastante durante dererminados períodos contábeis.

A fim de melhor demonstrar a diferença entre os dois métodos, recorremos a um exemplo numérico da demonstração de lucro anual de uma emprêsa, dividido em trimestres e calculado pelo método de absorção e de custeio direto (2). Nesta ilustração, tornam-se patentes as variações do lucro para determinadas quantidades de produção e vendas nos três casos de apuração de lucros trimestrais. (Vide Quadros 1 a 5).

Ao comparar os resultados obtidos no cálculo efetuado pelas três variantes, verificam-se variações substanciais na distribuição do lucro anual entre os quatro trimestres.

(2) N. A. C. A. Bulletin, «Direct Costing», abril de 1953, pgs. $1112-1113$. 
R.A.E.

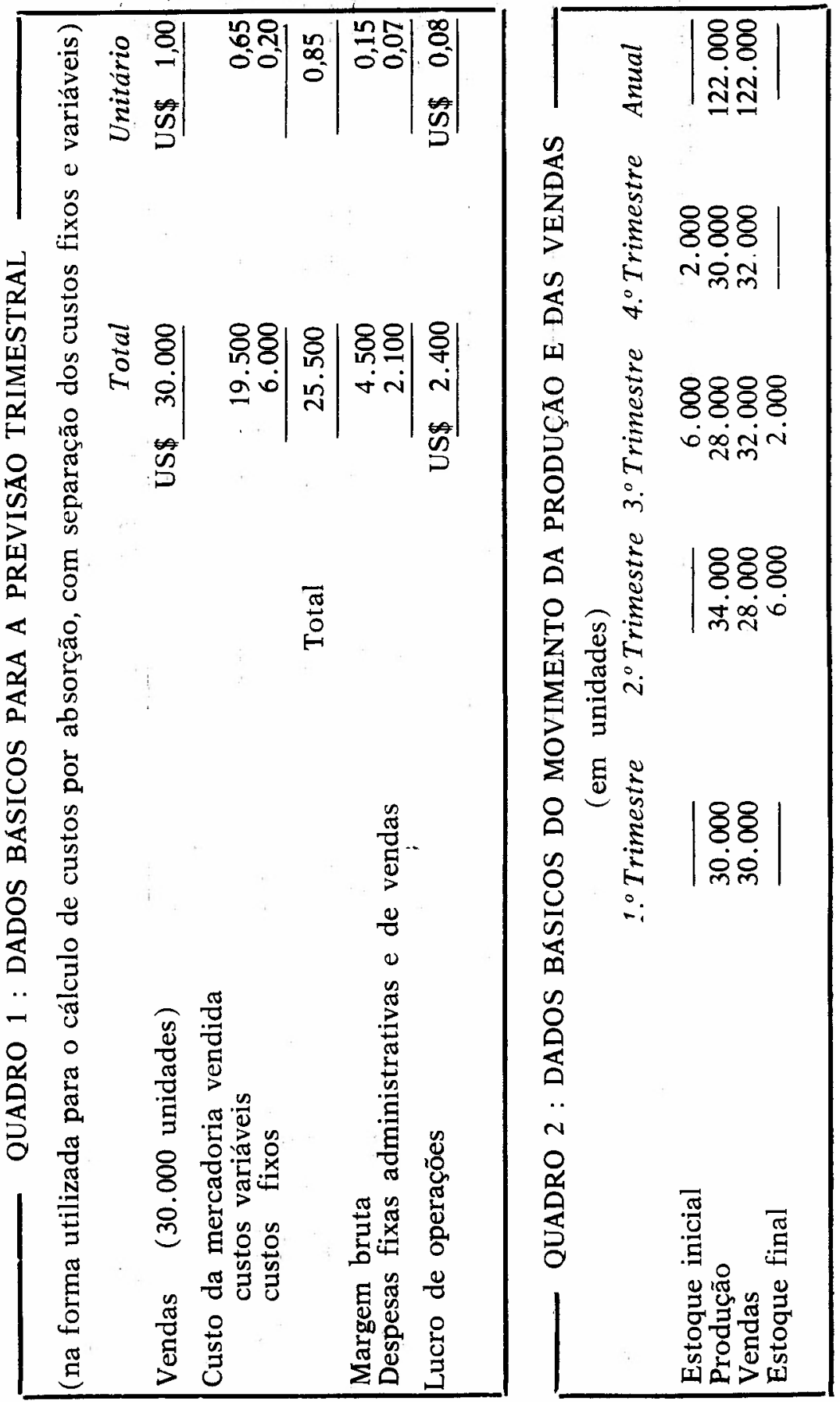




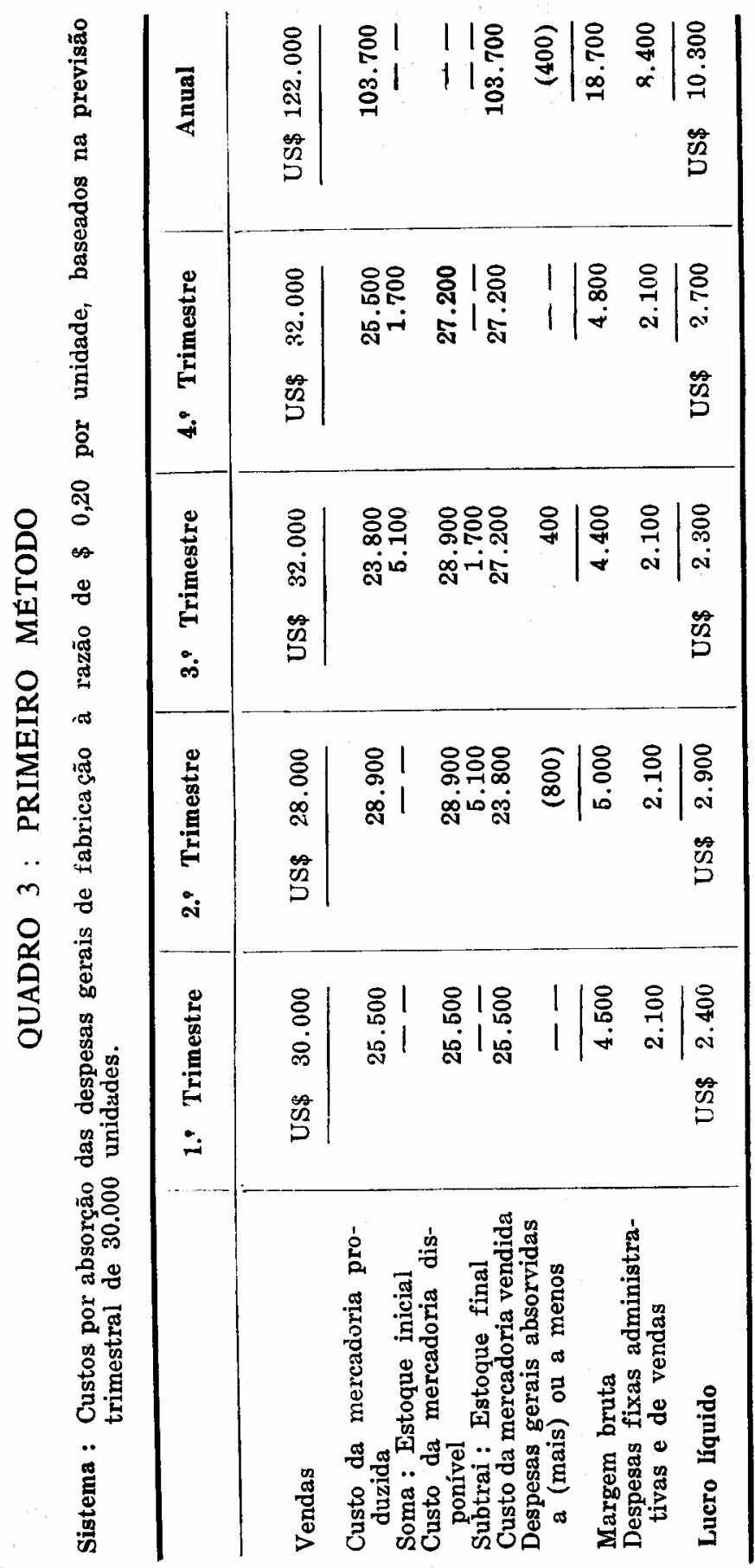




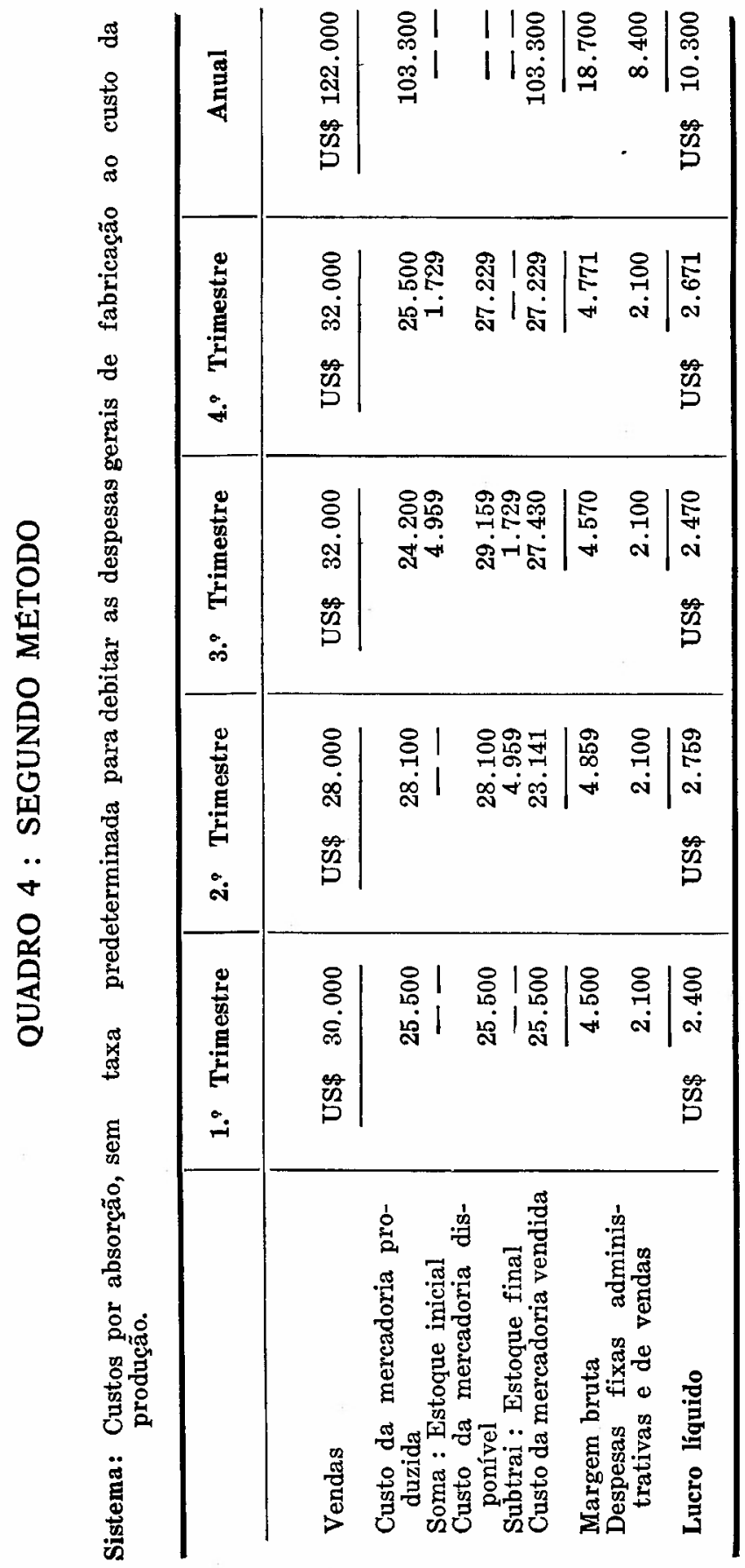




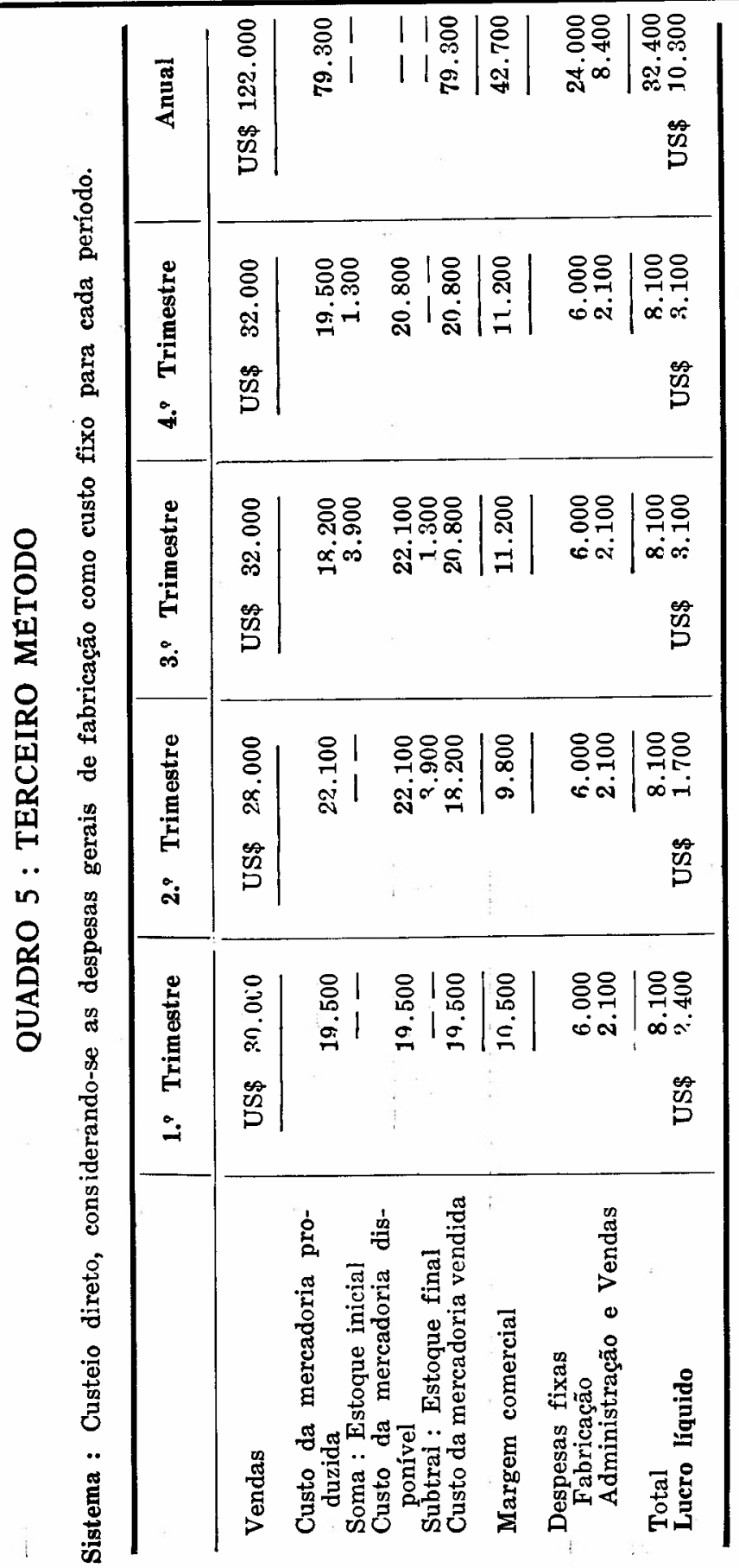


Apesar de um volume de vendas mais baixo no $20^{\circ}$ do que no $1 .^{\circ}$ trimestre, o lucro acumulado pelo método de custos por absorção aumentou no $2 .^{\circ}$ trimestre. No $30^{\circ}$ trimestre, a situação representa o inverso, isto é, para um volume de vendas maior, o lucro é menor do que em qualquer dos trimestres anteriores. No $4 .^{\circ}$ trimestre, o volume de vendas é o mesmo, mas há uma diferença de US $\$ 400$ no lucro, em relação ao trimestre anterior. Estas diferenças são devidas às variações das quantidades de produção e de vendas, considerando-se sempre constantes os preços de venda, os custos de produção e a linha de produtos. Na prática, ocorrerão variações para êstes fatôres, porém, a variação quantitativa sempre aparecerá da mesma forma em relação ao lucro apurado.

\section{Custeio Direto e Ponto de Paridade}

O ponto de paridade ("break-even point") é o ponto em que a receita é igual ao custo total, correspondendo a um determinado nível ou volume de operações. Este ponto também corresponde ao volume mínimo de operações necessário para cobrir todos os custos e, portanto, apenas acima dêste volume poderá ser auferido qualquer lucro. $O$ ponto de paridade pode ser expresso em unidades físicas, monetárias ou percentagem da capacidade total existente de produção.

A determinação do ponto de paridade é imprescindível para os casos de análise marginal do lucro quando, por exemplo, se deseja diminuir o preço de vendas para aumentar seu volume, com o objetivo de obter-se o lucro máximo em relação à capacidade produtiva disponivel. No ponto de paridade, não há lucro nem prejuízo e, em períodos mais difíceis, é também o ponto de referência para fixar níveis mínimos de atividade e diminuir eventuais prejuízos de operação.

O método do custeio direto possibilita uma rápida análise do ponto de paridade, efetuando-se a divisão das despesas gerais pela percentagem que a "margem comercial" representa da receita bruta de vendas. Em têrmos de custeio direto, o ponto de paridade em cruzeiros corresponde ao volume de 
vendas em que a "margem comercial" é igual às despesas gerais fixas. Assim,

$$
P=\frac{100}{M} \times F
$$

sendo,

P ... Ponto de paridade em cruzeiros

M ... Margem comercial ( $\%$ de vendas)

F ... Despesas gerais fixas

Exemplo: Utilizando os dados constantes do Quadro 5, calcular o ponto de paridade referente ao total produzido e vendido durante $o$ ano.

$$
\begin{aligned}
& M=35,0 \% \text { das vendas anuais } \\
& F=U S \$ 32.400
\end{aligned}
$$

Portanto,

$$
P=\frac{100}{35} \times \text { US } \$ 32.400=\text { US } \$ 92.571
$$

Conclui-se que o lucro anual de US $\$ 10.300$ é produzido por vendas acima do ponto de paridade, no total de US $\$ 29.429$, que é, justamente, a diferença entre o faturamento total de US\$ 122.000 e o ponto de paridade de US\$ 92.571. (Vide Gráfico I).

\section{A Prática da Determinação de Preços}

O exemplo anterior demonstra que o método do custeio direto pode ser utilizado com vantagem para uma série de decisões administrativas, sobretudo para aquelas que se relacionam com a determinação do preço em função da capacidade instalada de produção e da procura vigente no mercado.

Observações e estudos demonstram que o princípio clássico da determinação do preço pelo cálculo do seu custo total, adicionado de uma determinada percentagem de lucro, encontra dia a dia menor aplicação por parte dos administradores de emprêsas. Hoje, o administrador está muito mais 
interessado nos lucros totais de operação obtidos durante um determinado período, do que numa dada percentagem ou margem de lucro fixa por unidade.

GRÁFICO I: DETERMINAÇÃO dO PONTO DE PARIDADE REFERENTE À DEMONSTRAÇÃO DO LUCRO ANUAL (quadro 5) BASEADO NO MÉTOdO DO CUSTEIO DIRETO

$+$

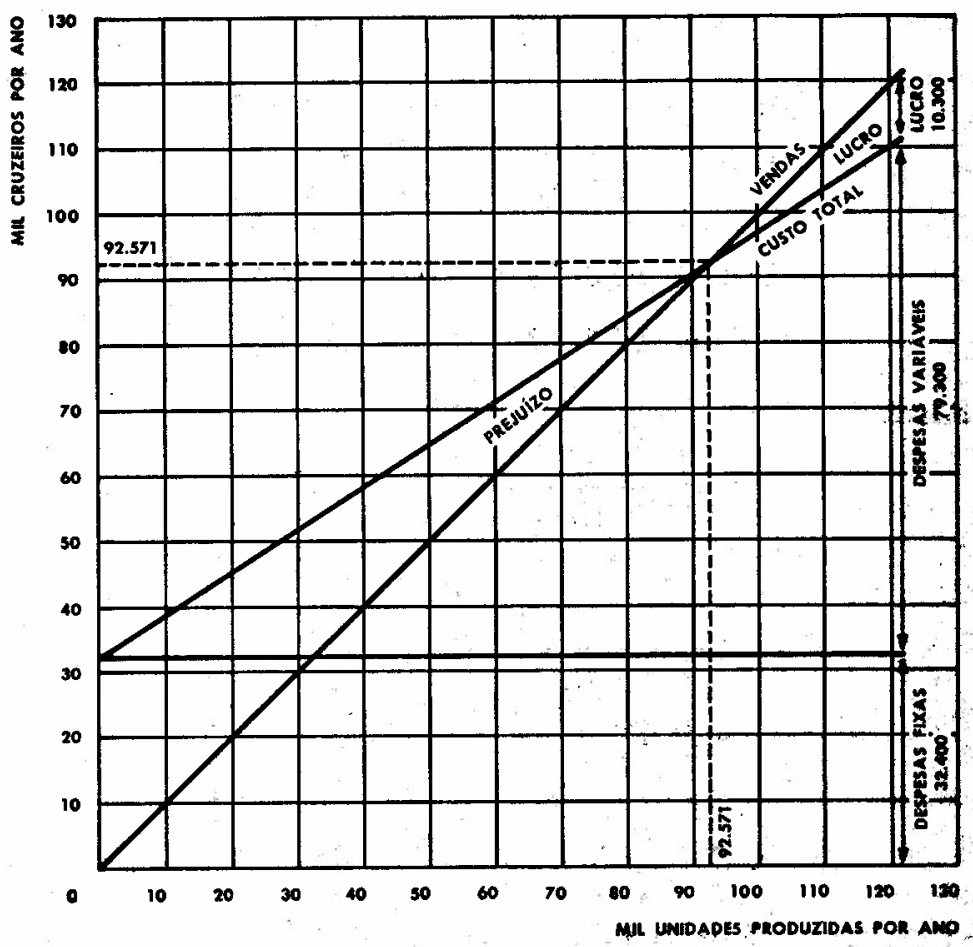

Na dinâmica dos negócios em uma economia livre, a concorrência representa a maior fôrça para a determinação do preço de produtos manufaturados, mas nem sempre a oferta e a procura resultam em preços bem definidos. Assim, alguns produtos são vendidos com pequena margem de lucros, quer porque seus fabricantes achem que esta margem é suficiente, quer porque não possuam cálculos corretos de custos. 
Por outro lado, a margem de lucro pode ser elevada em relação à remuneração do capital aplicado na emprêsa, quando assim também agem os concorrentes, ou quando, por insuficiência ou mesmo ausência dêstes, o mercado está disposto a pagar o preço exigido pelos fornecedores. É a chamada determinação do preço pelo princípio de "what the traffic can bear" em que produtores determinam o preço em função do máximo que o mercado está disposto a pagar pelo produto.

Entre nós, por exemplo, procura justificar-se frequientemente a manutenção, por parte dos produtores, de preços considerados elevados para certos produtos de grande demanda, pois, se diz, como o próprio mercado determina finalmente o preço, os produtores julgam que o preço para o consumidor seria sempre o mesmo, canalizando-se apenas um lucro maior para os intermediários de vendas. Este argumento tem sido utilizado por diversos representantes da nossa indústria automobilística, principalmente no comêço das suas atividades no país. Afirmavam que, devido à grande procura de veículos, tanto os concessionários como os consumidores acabariam vendendo pelo preço de mercado.

A fixação de preços de venda implica em tabelamento e está sobejamente provado que o contrôle de preços por tabelamento é contrário ao funcionamento das leis da oferta e procura. Daí resulta o fracasso da fixação de preços quando feita em bases diferentes da oferta do mercado, criando-se o mercado negro sempre que a procura é maior do que a oferta. Por outro lado, são concedidos descontos especiais aos compradores sempre que há maior oferta ou retração de compras.

\section{Capacidade Excessiva e Produtos Múltiplos}

Nầo existe, então, correlação entre preços e custos para um determinado produto? A resposta óbvia a esta pergunta é que existe uma relação para cada produto durante determinada época, pois, a longo prazo, nenhuma emprêsa pode sobreviver sem vender acima de um custo mínimo de operação. Contudo, como deve ser fixado êste custo? 
O método de custeio direto fornece uma resposta satisfatória a esta pergunta. Na classificação dos custos utilizada para o custeio direto, o custo primário, adicionado das despesas diretas de vendas, tais como comissões e impostos, pode ser considerado como constituindo o limite inferior do preço de venda.

Este critério é particularmente útil quando existe capacidade produtiva instalada, em excesso à demanda do mercado para um determinado preço. Este limite inferior corresponde ao desembôlso direto em dinheiro pela produção e venda do produto e considera-se que qualquer inportância que se consiga acima dêste limite constituirá pelo menos uma contribuição para absorver as despesas gerais, de natureza fi. xa. O custo primário adicionado das despesas diretas também pode ser chamado de custo variável - que os americanos denominam caracterìsticamente de "out-of-pocket expense".

Para emprêsas que produzem uma linha variada de produtos, o método do custeio direto permite, com grande facilidade, que uma maior proporção das despesas fixas seja absorvida pelos produtos que contam com um mercado em condições favoráveis, em benefício daqueles produtos cuja posição é desfavorável no momento, mas cuja eliminação prejudicaria a política comercial da emprêsa. Ao eliminar alguns itens, a emprêsa deixaria, talvez, de oferecer uma linha completa ao mercado, o que poderia resultar na perda de negócios nos setores mais lucrativos. Ainda assim, êsses mesmos itens podem contribuir para absorver um mínimo de despesas fixas.

\section{Absorção de Custos e Concorrência}

Sob certas condições, a absorção "a priori" das despesas fixas pelas linhas de maior lucratividade pode ser um poderoso instrumento para enfrentar a concorrência. Um exemplo disto foi oferecido ao mundo de negócios pela indústria química alemã, no período compreendido entre as duas Guerras Mundiais. Mesmo sem considerar a questão das patentes de processos, era muito difícil concorrer com a indústria química alemã em matéria de preços. Os grandes cartéis da indústria química, fabricando inúmeros produtos, possuíam substancial flexibilidade em relação à fixação dos 
respectivos preços para cada produto. Calculando os custos por um sistema que pode ser considerado uma aproximação do "direct costing", apresentavam-se, então, os seguintes procedimentos fundamentais :

a) - No cálculo dos produtos básicos não era levado a crédito o valor dos resíduos ou subprodutos resultantes de seu processo, quando o mercado assim o permitia. Estes resíduos que, por sua vez, dariam origem a um ou mais subprodutos e, portanto, constituíam a matéria-prima de outros processos, entravam com valor igual a zero no cálculo de custo dêstes subprodutos. Evidentemente, a chamada linha de subprodutos não era, assim, passível de concorrência.

b) - No caso em que os produtos básicos tivessem que enfrentar concorrência de preços, seria estudado até que ponto um ou mais outros produtos e subprodutos poderiam arcar com parte de seu custo fixo ou mesmo variável. Nesta hipótese, os subprodutos seriam contabilizados com determinados valores, diminuindo-se, assim, o custo de um produto básico e aumentando-se o custo do subproduto pelo maior valor atribuído à sua respectiva matéria-prima.

Em uma industrialização complexa como a de produtos químicos, fica bem patente que, com base nas premissas expostas, as variações de custo podem sofrer manipulações em número pràticamente infinito. Desta forma, determinadas indústrias não apenas mantém sua posição competitiva, mas chegam, eventualmente, a dominar completamente o mercado pela exclusão de concorrentes que serão fatalmente desencorajados pela queda artificial do preço dos produtos que desejarem lançar no mercado.

Nos Estados Unidos, o legislador proibe a venda abaixo do custo a fim de coibir a concorrência desleal e a formação de monopólios. Na prática, a comprovação do custo real, para efeitos legais, é sempre difícil e controvertida. Entre nós, a legislação ainda não é específica, neste ponto. 
Procura Irregular vs. Niveis Constantes de Produção

A análise dos custos pelo "direct costing" constitui, igualmente, valioso subsídio para determinar os limites práticos dos preços de venda, visando a obtenção de níveis constantes de produção.

Assim, para certos setores de nossa indústria, a conjuntura de negócios acarreta, periòdicamente, reduzida atividade industrial. O custeio direto indicará até que ponto as despesas variáveis e fixas serão cobertas em função de uma estrutura flexível de preços, mantendo constante o volume da produção. A simples redução dos níveis de produção, acompanhando a queda de vendas, normalmente agrava o custo unitário e, conseqüentemente, a emprêsa torna-se menos competitiva. E isto acontece justamente quando a situação exigiria um comportamento em direção oposta. Quando a capacidade de produção da emprêsa tiver atingido o seu limite superior para as instalações existentes e a demanda ainda exceder a capacidade de produção, então será conveniente estudar as possibilidades de expansão com elevação dos custos fixos.

Outro ponto será a repercussão, sôbre a rentabilidade, tanto do capital a ser invertido na própria expansão, como do capital atual. Ainda no caso de uma maior demanda não justificar uma expansão, resta considerar a possibilidade de limitar os pedidos aos níveis da produção, em virtude da criação de preços mais elevados.

Por isso, nos casos de flutuações freqüentes e apreciáveis, o sistema de custeio direto apresenta algumas vantagens indiscutíveis para a orientação do administrador, em relação ao traçado de diretrizes quanto à estrutura de preços e remuneração do capital empregado na emprêsa.

\section{Conclusões}

Nas emprêsas brasileiras que adotam o custeio direto, observa-se que, em virtude de limitações de ordem fiscal, a contabilidade oficial é realizada pelo processo tradicional, enquanto que o custeio direto é utilizado para fins internos de análise, estudos e decisões a respeito de política de preços e resultados financeiros. 
Normalmente, os sistemas convencionais de custo permitem a realização do custeio direto através do reagrupamento de seus dados contábeis. A prática de manter-se tôda a contabilidade de custos separada da contabilidade fiscal constitui um procedimento observado não apenas entre nós, mas também em muitos outros países. Isto não só é justificável, mas também se torna necessário, pelo fato de os resultados da contabilidade para fins fiscais não oferecerem os pormenores necessários ao perfeito contrôle financeiro dos diferentes setores de uma emprêsa.

Ao contrário do método tradicional de custos por absorção, o sistema do custeio direto separa os custos fixos de fabricação dos custos diretamente variáveis com a produção. Os custos fixos são diretamente levados à conta de lucros e perdas e equiitativamente distribuídos por períodos de produção. Desta maneira, o empresário obtém um dado de custo de mercadorias vendidas que, mais fieimente, reflete os gastos e esforços feitos nos respectivos períodos de produção. Por conseguinte, também o lucro líquido por pelíodos de produção e venda torna-se mais realista.

Além dessas vantagens, o custeio direto oferece meios mais precisos para o planejamento financeiro, sobretudo quando a emprêsa está sujeita a variações substanciais no seu volume de produção e de vendas, ou quando produz uma multiplicidade de produtos com diferentes graus de aceitação no mercado.

Oferece o custeio direto bases mais flexíveis do que o custeio por absorção para determinar preços em função da capacidade de produção e das condições impostas à emprêsa pelo mercado e pela concorrência, possibilitando a escolha de maior número de alternativas para as decisões administrativas.

\section{BIBLIOGRAFIA}

J. A. Beckett, «An Appraisal of Diret Costing», N.A.C.A. Bulletin, New York, dezembro de 1951.

J. A. Beckett, «Direct Costing in Perspective», N.A.C.A. Bulletin, Now York, janeiro de 1955 . 
J. G. Blocker e W. K. Weltmer, Cost Accounting, McGraw-Hill Book Co., New York, 1954.

E. G. Cox, «Applications of Direct Cost Principles», N.A.C.A. Bulletin, abril de 1958 .

C. Gillespie, Cost Accounting and Control, Prentice-Hall, Englewood Cliffs, New York, 1957.

J. N. Harris. «Direct Costs as an Aid to Sales Management». The Controller, outubro de 1948.

I. W. Keller, Management Accounting for Profit Control, McGraw-Hill Book Co., New York, 1957.

N. A. C. A. Bulletin, Research Series n. $^{\bullet} 23$, «Direct Costing», New York, abril de 1953.

F. Whle, Plan-und Standardkostenrechnung, Girardet, Essen, 1952. 